\begin{tabular}{|l|l|l|}
\hline T.L. & Terri L. & Harpold \\
\hline J. & Gordon & McComb \\
\hline M.L. & Michael L. & Levy \\
\hline
\end{tabular}

Los Angeles, Calif., USA

\title{
Dermal Inclusion Cyst Associated with Repaired Myelomeningocele
}

Dr. J. Gordon McComb, Division of Pediatric Neurosurgery, 1300 N Vermont Avenue, No. 906, Los Angeles, CA 90027 (USA), Tel. +1 (213) 6638128 , Fax +1 (213) 668 1870
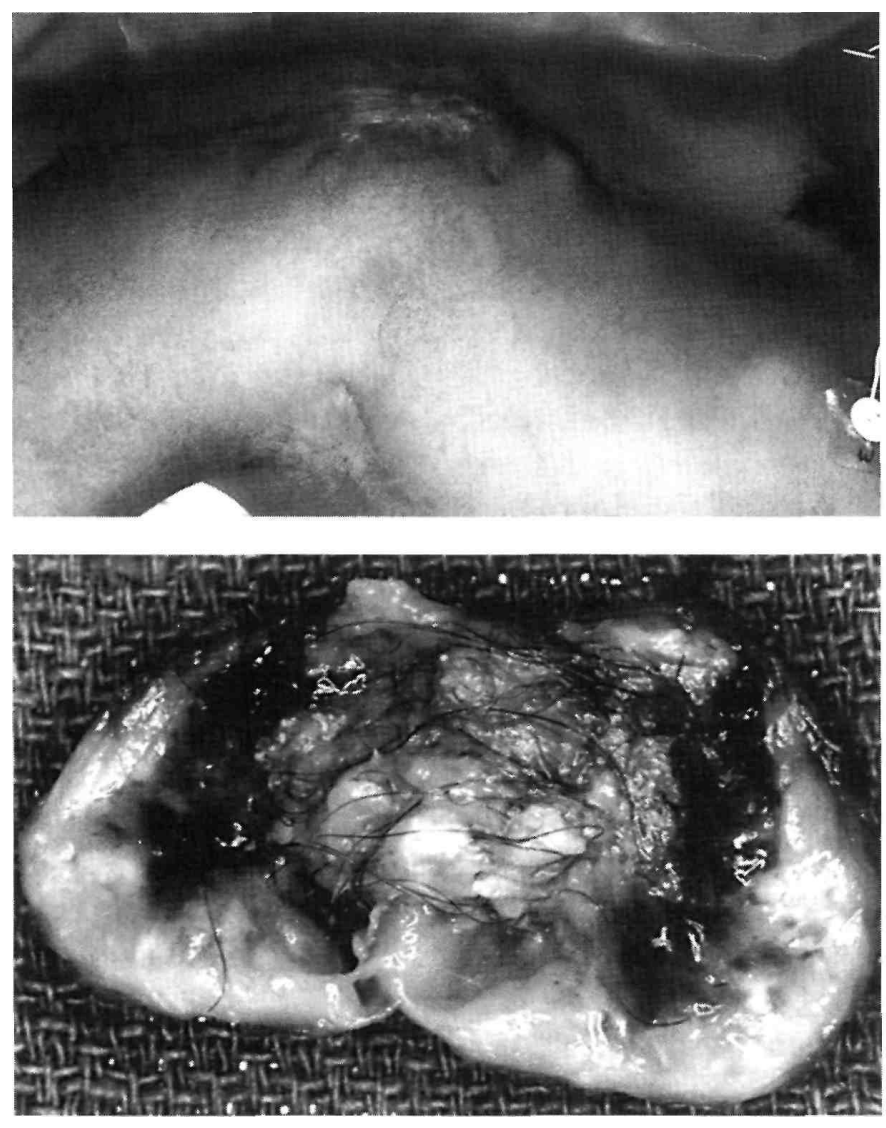

Fax + 41613061234 E-Mail karger@karger.ch www.karger. com (C) 1997 S. Karger AG, Basel

1016-2291 97/0266-0326\$ 15.00/0

This article is also accessible online at: http://BioMedNet.com/karger

\section{KAI $\backslash$ GEK}

An 8-year-old girl with a myelomeningocele repaired at birth presented for the first time to our hospital with back pain and purulent drainage from her repair site; on close inspection of the area, a small orifice was noted through which numerous hairs extruded and purulent debris exuded (fig. 1, 2). Diagnosis: dermal inclusion cyst associated with a repaired myelomeningocele (fig. 3).

At operation, a sinus tract was traced to dermal elements attached to the neural placode and completely resected. The lateral aspects of the neural placode were approximated in midline to reduce scarring and subse-

quent tethering. Microscopic examination of the excised mass revealed the typical components of a dermal inclusion cyst to include hair follicles, sebaceous glands, keratin debris, and viable squamous epithelium.

This case illustrates the importance of excluding all viable epithelial elements from the neural tube at the time of initial repair. One sequela of incorporating skin elements is that of the patient pictured: localized infection and purulent drainage from a fistula. Another can be progressive compression of surrounding neural structures from an enlarging dermoid. Contrary to a congenital dermal sinus, if an infection occurs, it usually remains localized rather than producing meningitis or an extensive abscess within the spinal cord.

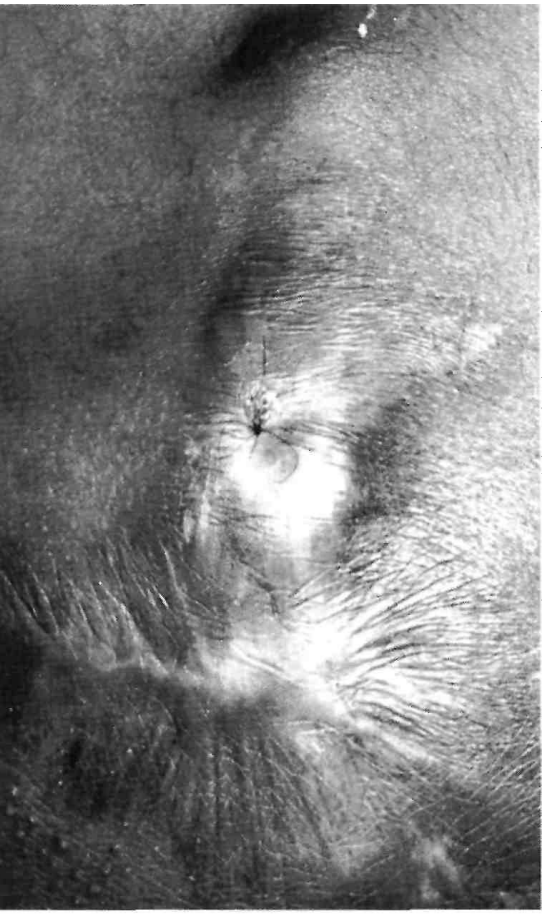

